\title{
RESEARCH ON SHEAR CONNECTION DESIGN IN COMPOSITE BEAMS
}

The paper deals with a way of determining concrete pressure strength when calculating load carrying capacity of steel perfobond strip connectors. This type of strip connectors has been used in composite bridges only recently and no precise methods of calculating them have been worked out so far. The effect of axial forces on bearing capacity of classical stud shear connectors is also given in the paper as a result of research.

\section{Introduction}

There is no explicit definition of concrete pressure strength because there are no standard principles of defining this strength. This is why it may be difficult to adopt design values for particular classes of concrete in actual engineering practice. Moreover, the experimental investigations in this field are done on different samples for different areas of pressure. Hence, significant discrepancies exist in the propositions by various authors, and even norm values.

The stud connector's behaviour depends not only on their bearing and shear resistance. The axial forces may modify importantly the ultimate load bearing capacity. The effect of this action is also given in the paper as a result of research.

\section{Test elements and research methodology}

In case of perfobond strip connectors, there are special conditions of concrete pressure. It is a pressure of two cylindrical surfaces of small dimensions. The strips thickness range can be from $t=12 \mathrm{~mm}$ to $20 \mathrm{~mm}$, and the diameter of holes is from $\Phi=30 \mathrm{~mm}$ to $40 \mathrm{~mm}$.

Moreover, the distribution of pressure stress on the concretestrip contact area differs in comparison to classical cases. It can be assumed to be close to the one adopted by Hertz's formulae. However, these formulae cannot be adopted for calculating $\bar{f}_{\text {end }}$ because of significant non-homogeneity of concrete and big differences between mechanical characteristics of aggregate and cement set. Moreover, the relatively thin steel strip acts on concrete like a wedge.

Due to the specific character of problems of concrete pressure in perforated strips, the only solution seems to be experimental investigations. They are recommendable also because of the limited range of values of the essential parameters, i.e. strip thickness, hole diameters and concrete class.

The sizes of the elements used in tests are shown in Fig. 1. The elements were cubes of a side $a=150 \mathrm{~mm}$, with an additional bulge in the shape of a half-round of diameter matching the diameter of the holes in the perforated strips used in steel-concrete composite structures. The pressure force has been transferred by a steel element with a half-round of the same diameter as the bulge on the concrete cube and the thickness corresponding to the thickness of the strip.

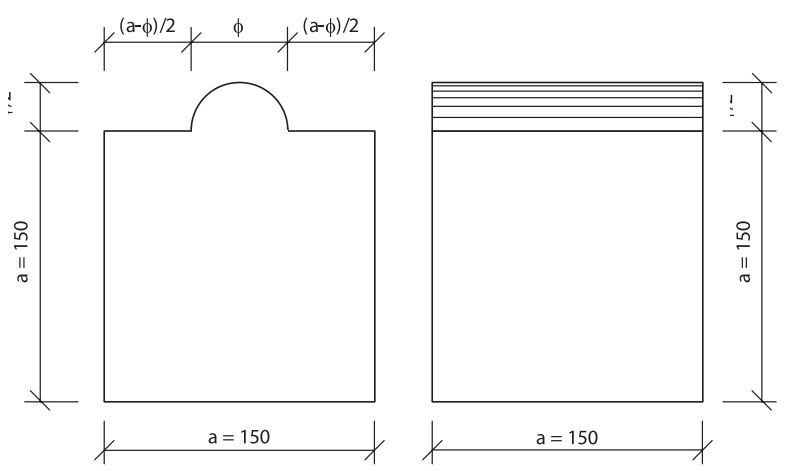

Fig. 1 Shape and dimensions of test samples

For the adopted shape of the test elements, concrete ultimate pressure strength was obtained, which can be used directly in calculating perfobonds load carrying capacity. To this aim, the following test parameters were adopted: thickness of perfobonds, diameters of holes and concrete class.

Three classes of concrete were used: $\mathrm{C} 30 / 37, \mathrm{C} 40 / 50$ and C50/80 with three diameters of holes: $\Phi=20,30$ and $40 \mathrm{~mm}$ and

\footnotetext{
* Ján Bujňńk ${ }^{1}$, Kazimierz Furtak ${ }^{2}$

${ }^{1}$ Faculty of Civil Engineering, University of Žilina. Komenského 52, 01026 Žilina, Slovakia. E-mail: bujnak@fstav.uniza.sk

${ }^{2}$ Department of Bridges and Tunnels Building, Faculty of Civil Engineering, Cracow University of Technology. Warszawska 24, 31155 Cracow, Poland
} 
three thickness of the strips: $t=12,16$ and $20 \mathrm{~mm}$. The basic parameters used were: the concrete class $\mathrm{C} 40 / 50$, the diameter of a hole $\Phi=30 \mathrm{~mm}$ and the strip thickness $t=16 \mathrm{~mm}$. As a total, the 114 elements have been examined.

The tests were run on a standard testing machine. The rate of loading was $0.4 \mathrm{MPa} . \mathrm{s}^{-1}$, the given stress was calculated by dividing the pressure force by the product of strip thickness and hole diameter. The tests elements were stored in normal laboratory conditions.

\section{Test results and their analysis}

The tests of strength characteristics of the concrete from which the test elements were made had provided the following values of concrete mean compressive strength $\bar{f}_{c}$ and tensile strength $\bar{f}_{t}$ :

- Concrete class C30/37: $\bar{f}_{c}=34.80 \mathrm{MPa} \quad \bar{f}_{t}=2.36 \mathrm{MPa}$,

- Concrete class C40/50: $\bar{f}_{c}=45.96 \mathrm{MPa} \quad \bar{f}_{t}=3.08 \mathrm{MPa}$,

- Concrete class C50/80: $\bar{f}_{c}=61,10 \mathrm{MPa} \bar{f}_{t}=4.10 \mathrm{MPa}$.

The concrete compressive and tensile strength for splitting were determined on cubes of sides of $150 \mathrm{~mm}$. For strength characteristics tests $\left(\bar{f}_{c}, \bar{f}_{t}\right)$, each series have contained six elements. The tests were done in a standard way. The cubes for $\bar{f}_{c}$ and $\bar{f}_{t}$ were stored in natural conditions, similarly as samples for compressive tests.

The results of the compressive tests are shown in Figs 2 to 5 . Fig. 2 illustrates the effect of strip thickness for different concrete classes, while Fig. 3 the effect of diameter of holes. As it can be clearly seen, there is a strong decreasing tendency of compressive strength $\bar{f}_{c u d}$ with the increase of strip thickness and hole diameters. The approximately linear change of concrete strength $\bar{f}_{c u d}$ dependence on $t$ and $\Phi$ is worth to underline.

For design purpose, it is much more useful to have concrete compressive strength $\bar{f}_{\text {cud }}$ as a function of the pressure area $A_{p}=$ $t \cdot \Phi$. This pressure can be defined as a product of the strip thickness $t$ and the diameter of holes $\Phi$. This is a simplification due to adopted assumption of the mean values of stresses. In reality, the distribution of stresses on the pressure semi-perimeter is quite variable, especially in the case of homogeneous materials.

The effect of pressure area $A_{p}$ on concrete strength $\bar{f}_{\text {cud }}$ is illustrated in Fig. 4. The dependence is clearly non-linear and may be well approximated by a logarithmic function. Generally, with the larger pressure area the lower $\bar{f}_{\text {cud }}$ strength results. However, it should be noted that the decrease of pressure strength in real practical ranges of pressure area is even doubled.

Fig. 5 shows the dependence of the concrete pressure strength $\bar{f}_{\text {cud }}$ on its class (represented by compressive strength $\bar{f}_{c}$ ) and pressure area $A_{p}$.

The results of experimental investigations illustrated in Figures 2 to 5 are an arithmetic mean obtained from the whole series of 3

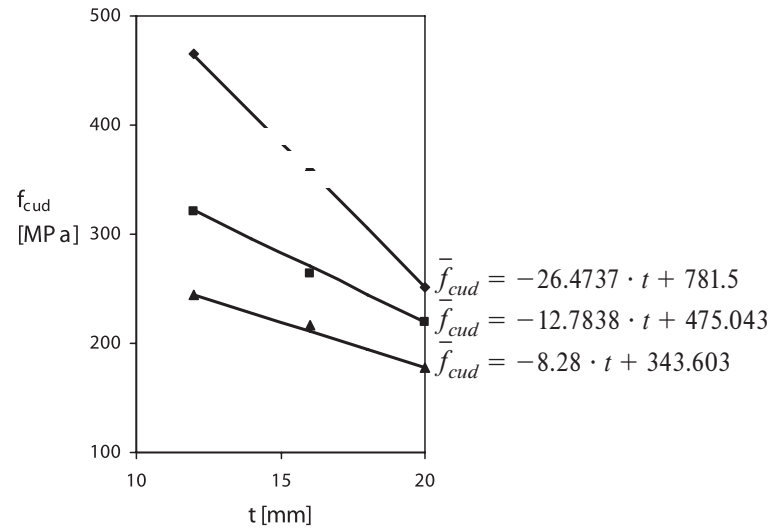

Fig. 2 Effect of strip thickness on pressure strength of concrete class $C 40 / 50$

to 6 elements. The figures show approximation curves, which can be used for determining concrete pressure strength when designing perforated strips in composite structures.

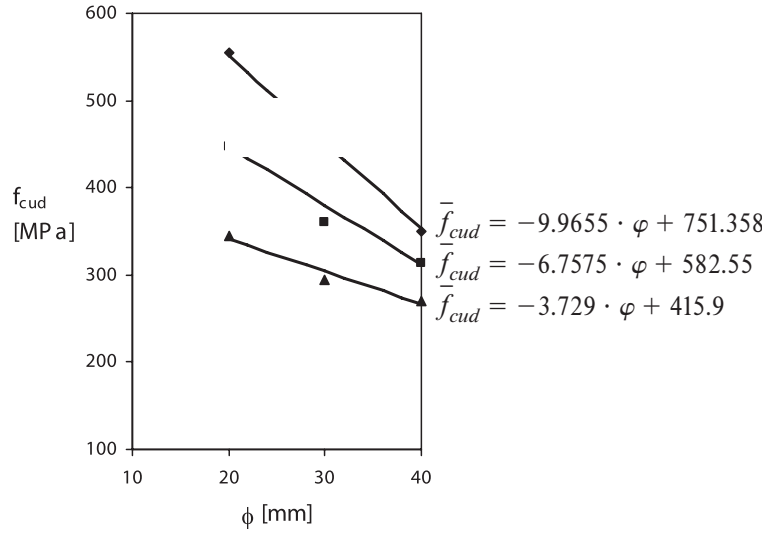

Fig. 3 Effect of hole diameter on pressure strength of concrete class B 40

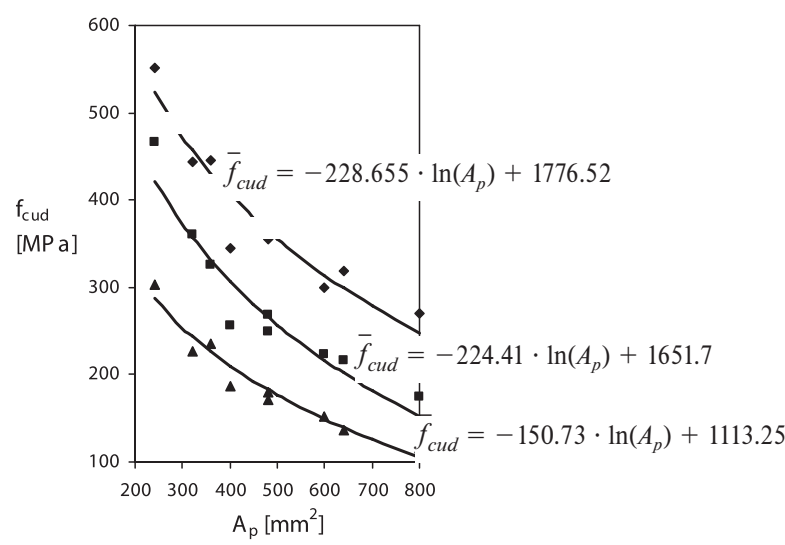

Fig. 4 Effect of pressure area on pressure strength of concrete

For design purposes, it can be preferable to have a simultaneous dependence of concrete pressure strength $\bar{f}_{\text {cud }}$ on compressive 
strength $\bar{f}_{c}$ and pressure area $A_{p}$. Dependence $\bar{f}_{\text {cud }}=\bar{f}_{c u d}\left(\bar{f}_{c}, A_{p}\right)$ can be written as:

$$
\begin{aligned}
& \bar{f}_{\text {cud }}=\left(8.30 \cdot \bar{f}_{c}-56.70\right) \cdot \kappa \\
& \kappa=1.46 \cdot \lambda^{0.4}+2.46 \\
& \lambda=\frac{A_{p}}{360}
\end{aligned}
$$

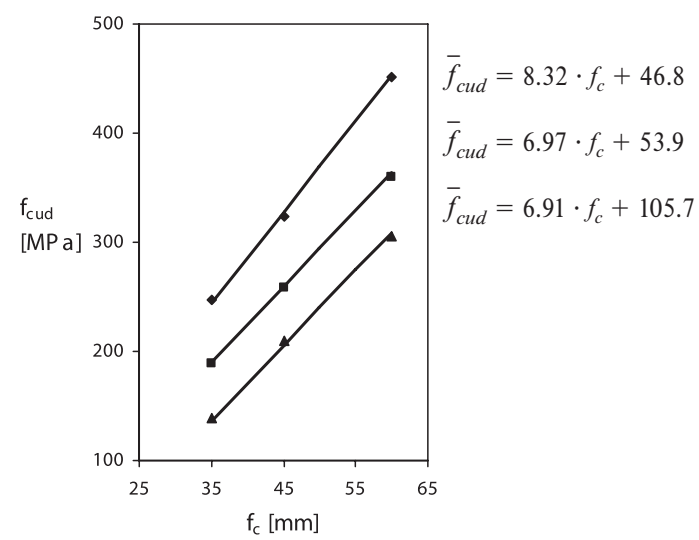

Fig. 5 Dependence of pressure strength on concrete class and pressure area

In the formulae above $\bar{f}_{c}$ and $\bar{f}_{\text {cud }}$ are expressed in [MPa] and the pressure area $A_{p}=t . \Phi$ in $\left[\mathrm{mm}^{2}\right]$. Formula (1) is valid for $360 \mathrm{~mm}^{2} \leq A_{p} \leq 600 \mathrm{~mm}^{2}$. It gives the mean strength. The characteristic strength $\bar{f}_{\text {cudk }}$ and design one $\bar{f}_{\text {cud }}$ can be determined using the same calculations as for concrete compressive strength.

\section{Influence of axial forces on shear strength}

The normal forces across the concrete and steel interface in the direction of the axis of the stud connector shank apply concentrated local loads. Bearing of the slab onto the steel beam flange resists the axial compressive forces and they rarely pose a problem. In contrast, the axial tensile actions can cause a separation between the composite elements or more often embedment concrete slab cracking. The shear strength of stud connectors is strongly influenced by the axial force across the steel and concrete interface. This resulting strength of push-test in which the base is free to slide [4] is substantially less than in the case of the fixed base [6]. This reduction in shear strength is due to the change of the resultant axial force at the interface from compression when the base is fixed to tension for the studs in the case of sliding base. The shear strength of headed studs can be degraded up to a third when the base is free to slide. The value of embedment forces in composite beams is generally considerably less than in the pushtests because of the difference between the boundary restraint conditions in the two systems.

The axial load can cause failure of the stud shank at the axial tensile strength

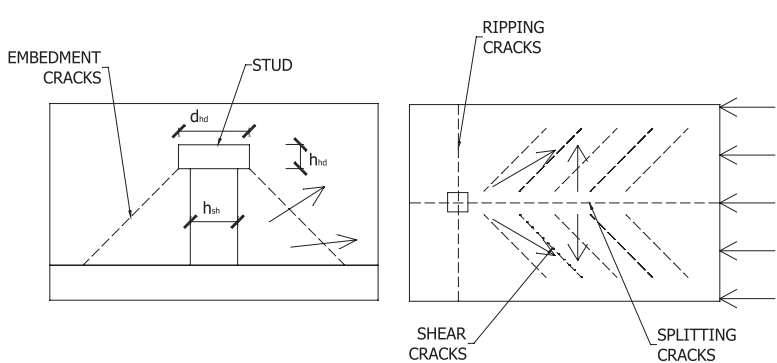

Fig. 6 Conical failure plane, dimensions of the stud connector

$N_{d}=A_{s h} \cdot f_{u}$,

where $A_{s h}$ is the cross-sectional area of the stud shank and fu its design tensile strength.

Alternatively, the connector can be pulled out of the slab forming a concrete cone around it (Fig. 6). The surface area of this conical failure plane is used for deriving the following axial embedment strength

$$
N_{d}=1.5 \cdot \sqrt{f_{c k}} \cdot h_{s h}\left(h_{s h}+d_{h d}\right),
$$

in which $f_{c k}$ is the compressive cylinder strength of the concrete and the remaining dimensions are defined in Fig. 6.

The shear dowel strength of stud connectors is given by a standard equation

$$
P_{d}=0.8 \cdot f_{u} \cdot \frac{\pi \cdot d s h^{2}}{4},
$$

the other equation should control shear connector steel shank strength

$$
P_{d}=0.29 \cdot \alpha \cdot d_{s h}^{2} \cdot \sqrt{f_{c k} \cdot E_{c m}} .
$$

\section{Interaction between shear and axial forces}

The axial forces on the shear connection can produce the elements separation. As a result, the tensile force at the stud head increases and the probability of embedment failure becomes greater. The critical tensile failure in the weld collar zone is in the same time more likely to fail when the axial tensile forces are applied. It is therefore necessary to determine the interaction between shear and axial effect.

The elliptical interaction curve proposed in [5] is

$$
\left(\frac{P_{S d}}{P_{d}}\right)^{\frac{3}{2}}+\left(\frac{N_{S d}}{N_{d}}\right)^{\frac{3}{2}}=1.0 .
$$

This failure envelope is represented in Fig. 7.

The alternative method of considering effect of axial forces on the shear strength of connectors is based on changing the tensile strength of the connector [6]. If the axial tensile stress $\sigma_{S d}=N_{S d} / A_{s h}$ 


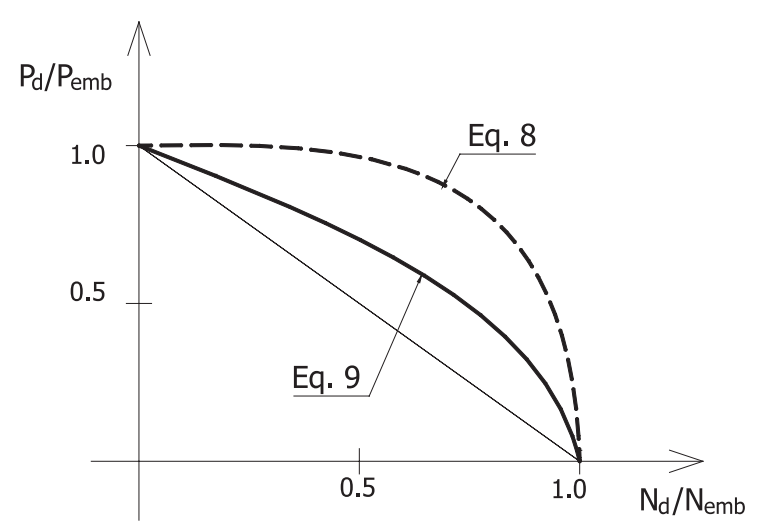

Fig. 7 Shear-axial failure envelope

is applied, the equivalent design tensile strength of a connector is reduced by relationship

$$
R_{d, e k v}=\left(1-\frac{\sigma_{S d}}{f_{u}}\right) \cdot R_{d} .
$$

It can be seen in Fig. 7 that the expression for quantifying the effects of axial forces on the shear strength of stud connector is a lower bound to the previous failure envelope.

\section{Conclusions}

The paper deals with concrete pressure strength $\bar{f}_{\text {cud }}$ in strip connectors of composite structures. The propositions of deter- mining $\bar{f}_{\text {cud }}$ have been based on the results of the experimental investigations, which were done within the framework of the grant of the Committee for Scientific Research.

The formulae quoted are valid for the parameters of strip thickness, hole diameters and concrete class adopted in the research They cannot be extrapolated beyond the extreme values of $\Phi$ ( 20 $\div 40 \mathrm{~mm}), t(12 \div 20 \mathrm{~mm})$ and $A_{p}\left(360 \div 600 \mathrm{~mm}^{2}\right)$. Interpolation is possible in the range of the given maximum values.

In design of a composite concrete slab with a steel girder using perforated strips, it can be considered as minimum value of pressure strength $f_{c p}=\omega \cdot f_{c}=4 \cdot f_{c}$ with pressure area not larger than $600 \mathrm{~mm}^{2}$ and concrete class at least B30. With pressure area not exceeding $360 \mathrm{~mm}^{2}$ and concrete class at least B30 even $\omega=5$ can be adopted.

Mechanical connectors impose very high concentrated load onto the concrete element. The load is transferred from the steel beam to the concrete through the dowel action of the connectors. The tensile cracks caused by shear and splitting actions can be avoided by design procedures in [7]. The embedment cracks caused by tension, resisting separation at the steel and concrete interface of composite beam can be assessed according to the described procedure.

\section{Acknowledgment}

This work was supported by the Slovak Research and Development Agency under the contract No. APVV-20-010005".

\section{References}

[1] PN-B-03264: 1999: Concrete, Composite Steel and Concrete Structures (in Poland), Obliczenia statycznei projektowanie.

[2] PN-84/B-03264: Concrete, Composite Steel and Concrete Structures (in Poland), Obliczenia statyczne i projektowanie.

[3] PN-91/S-10042: Bridge Objects - Concrete, Composite Steel and Concrete Structures (in Poland), Projektowanie

[4] OLlGAARD, J. O., SLUTTER, R. G., FISHER, J. W.: Shear Strength of Stud Connectors on Light Weight and Normal Weight Concrete, Engineering Journal AISC, April 1971

[5] BUJŇÁK, J.: Designing of Composite Steel and Concrete Beams (in Slovak), Vydavatel'stvo ŽU v Žiline, 1997

[6] BUJŇÁK, J., FURTAK, K.: Structural Elements from Steel and Concrete (in Slovak), Vydavatelstvo ŽU v Žiline, 1999

[7] BUJŇÁK, J., FURTAK, K., VIČAN, J.: Structure Designing by Eurocods (in Slovak), EDIS, Žilinska univerzita, Zilina, 2003. 